\title{
NEARSHORE WAVE PREDICTIONS ALONG THE OREGON AND SOUTHWEST WASHINGTON COAST
}

\author{
Gabriel García-Medina' ${ }^{1}$ H. Tuba Özkan-Haller ${ }^{1,2}$, and Peter Ruggiero ${ }^{2}$
}

\begin{abstract}
A nearshore wave forecasting system was implemented to elevate the ocean information resources in the US Pacific Northwest region. This implementation brings the US State of Oregon and the Southwest region of the state of Washington to the same level of prediction as the neighboring state of California and other regions of the country. It was achieved using the Wavewatch III numerical wave model, which was validated in intermediate to shallow waters. The forecasting system provides data at a 30 arc-second resolution from the shelf break up to a depth of 20 meters. The data is distributed to the public at no cost as part of a greater initiative put together by the Networked Association of Ocean Observing Systems. Information generated by this implementation is presently being used to provide boundary conditions to localized applications in the region as well as to beach users.
\end{abstract}

Keywords: Wavewatch III; Wave Forecasting; US Pacific Northwest

\section{INTRODUCTION}

The Pacific Northwest Region of the United States of America is characterized by one of the most severe wave climates in the northern hemisphere with at least one event per year exceeding significant wave height (SWH) of $10 \mathrm{~m}$ in deep water (Ruggiero et al. 2010). In addition, its narrow continental shelf combined with the presence of canyons, shoals and capes that are capable of influencing the waves make it a potentially hazardous place for navigation and recreational activities. Alongshore variations in wave height are present due to both the bathymetric features and multi-modal unsteady offshore sea-states. Unfortunately, only a few offshore buoys that provide real-time information are located along this coastline. Only three of these are deployed in water depths of less than $50 \mathrm{~m}$. On the other hand, the United States Government produces wave forecasts for the entire country but at a resolution that is not high enough to account for local variations in the bathymetry. The coasts of Oregon and Washington are visited by hundreds of thousands of visitors yearly, have many important commercial ports and are experiencing a variety of coastal hazards, such as dune erosion and coastal flooding. These, among other reasons, motivate the implementation of a high-resolution localized wave forecasting system which will lead to more informed users and facilitate decision making.

\section{METHODOLOGY}

\section{Wave Forecasting System}

The wave forecasting system was built by implementing a localized version of Wavewatch III version 3.14 developed by the National Oceanic and Atmospheric Administration (Tolman 2002, 2008). This is a third-generation wind wave model based on balancing the wave action equation with a series of parameterized source and sink terms. In our implementation we consider wave growth by wind energy input, steepness limited wave breaking (whitecapping), non-linear quadruplet wave interactions, and energy dissipation due to bottom friction and depth-induced wave breaking. Wind predictions are provided by NOAA's Global Forecasting System (GFS) (Sela 1980) at a 30 arc-minute resolution globally. The wind fields at $10 \mathrm{~m}$ height are used to force the numerical model for an 84 hour forecast horizon. Our forecasting model (NearWW3) is run daily with the nowcast being at 1200 UTC (synoptic time). To update our initial conditions, a 24 hour hindcast is run before the start of the forecasting model. The model forcing for this hindcast comes from NOAA's Global Data Assimilation System (GDAS); analyzed wind fields at $10 \mathrm{~m}$ height and air-sea temperature differences are used. This results in a more accurate representation of the initial sea-state.

In order to keep computational costs at a minimum, four levels of nested grids were implemented in NearWW3 with increasing resolution shoreward. The two-way nesting technique by Tolman (2008) was used, in which data from higher resolution models is consolidated at common time steps. To be able to predict distant swell coming from the southern and western Pacific Ocean, a large scale model was implemented. At a resolution of 1 by 1.25 arc-degrees, based on the operational Wavewatch III by

\footnotetext{
${ }^{1}$ School of Civil and Construction Engineering, Oregon State University, 104 CEOAS Admin Bldg., Corvallis, OR, 97331, USA.ggarcia@coas.oregonstate.edu

${ }^{2}$ College of Earth, Ocean, and Atmospheric Sciences, Oregon State University, 104 CEOAS Admin Bldg., Corvallis, OR, 97331, USA
} 
the National Centers for Environmental Prediction (NCEP), the oceanic behavior is represented by covering the Pacific and Indian Oceans. This model provides boundary data to a 15 arc-minutes resolution model, also based on NCEP's operational model, which itself provides boundary data for a local 3 arc-minute resolution model. The latter model covers a region from the $41.45^{\circ} \mathrm{N}$ to the $47.50^{\circ} \mathrm{N}$ and from the $127^{\circ} \mathrm{W}$ shoreward, providing the last intermediate nesting step. The region covered by this model is shown as a black rectangle in Figure 1A. The last level of computation covers a region from the $41.50^{\circ} \mathrm{N}$ to the $47.35^{\circ} \mathrm{N}$ extending from the shelf break to the shore. For computational purposes the region is divided in three grids as shown in Figure 1A.

\section{Study Area}

The area of interest covers more than 650 kilometers in the alongshore direction. A series of major features shape the bathymetry; e.g. the Astoria, Willapa, Guide, and McArthur Canyons; the Stonewall, Siltcoos, Perpetua, and Heceta Banks; and capes Arago and Blanco; among others. At a 30 arc-second resolution, the major bathymetric features with the potential of affecting the nearshore wave field are represented in the operational forecasting model. For example, Figure 1B shows a region from northern Oregon and southern Washington where the Astoria Canyon heads offshore approximately 18 kilometers west of the Columbia River Mouth. This canyon has the potential effect of causing refraction of the wave rays, generating alongshore gradients in the wave field in the nearshore. Figure $1 \mathrm{C}$ shows the bathymetry near central Oregon, where multiple banks reach depths as shallow as 80 meters at more than 60 kilometers offshore. These banks have the capacity of refracting swell and focusing the wave energy in several regions. Figure 1D shows the bathymetry offshore of southern Oregon, where the continental shelf narrows and multiple canyons and banks are present. These are some of the major bathymetric features that are well represented in NearWW3.

The PNW is characterized as a highly energetic region suitable for wave energy harvesting with a monthly median winter swell wave power of $37 \mathrm{~kW} / \mathrm{h}$ (Arinaga and Cheung, 2012). Figure 2 shows 18 years of wave data from an operational buoy offshore of central Oregon. Since 1997 several events have exceeded SWH of $10 \mathrm{~m}$; in addition waves with periods larger than $20 \mathrm{~s}$ are common. This region experiences a seasonal cycle where waves in the winter tend to be larger than during the summer. During this period the maximum wave height recorded at this location was $14 \mathrm{~m}$. In addition, several independent researchers have found evidence of an inter-decadal increase of wave heights (Menéndez et al. 2008; Ruggiero et al. 2010; Young et al. 2011). Further, the extreme events (eg. $99^{\text {th }}$ percentile, annual maximum, etc.) appear to be increasing at a higher rate (Ruggiero et al. 2010; Young et al. 2011).

\section{VALIDATION}

\section{Data}

To validate and assess the model performance, data collected from two field experiments on the Oregon coast were used. These experiments involved the deployment of two acoustic wave and current (AWAC) sensors, one near Reedsport and the other near Newport (Kirincich et al. 2009). The AWAC at Reedsport (RP) was deployed from September 18, 2009 to December 2, 2009 under very energetic conditions at 40 meters water depth. The average SWH and peak wave period (PWP) were $2.5 \mathrm{~m}$ and 11.1s. The Newport dataset includes two deployments (NPS and NPN). NPS acquired data from June 15,2005 to July 13, 2005 at $15 \mathrm{~m}$ water depth while NPN was deployed from July 23, 2005 to September 22, 2005 at $13 \mathrm{~m}$ water depth. NPS and NPN averaged smaller SWHs, $1.3 \mathrm{~m}$ both, and smaller PWPs, $8.5 \mathrm{~s}$ and $8.9 \mathrm{~s}$, respectively.

Other long term intermediate water deployments were used for model validation. NOAA's National Data Buoy Center (NDBC) and the Coastal Data Information Program (CDIP) from the Scripps Institution of Oceanography operate a network of buoys covering the PNW among other regions. Three of these buoys are located in intermediate waters inside our region of interest. Bulk wave parameters were downloaded from Buoys 46211, 46243, and 46027 measured for the same time period as the RP deployment. These buoys are located at $38 \mathrm{~m}, 25 \mathrm{~m}$ and $48 \mathrm{~m}$ water depth, respectively. The locations of both the short and long term deployments are mapped in Figure 3. 

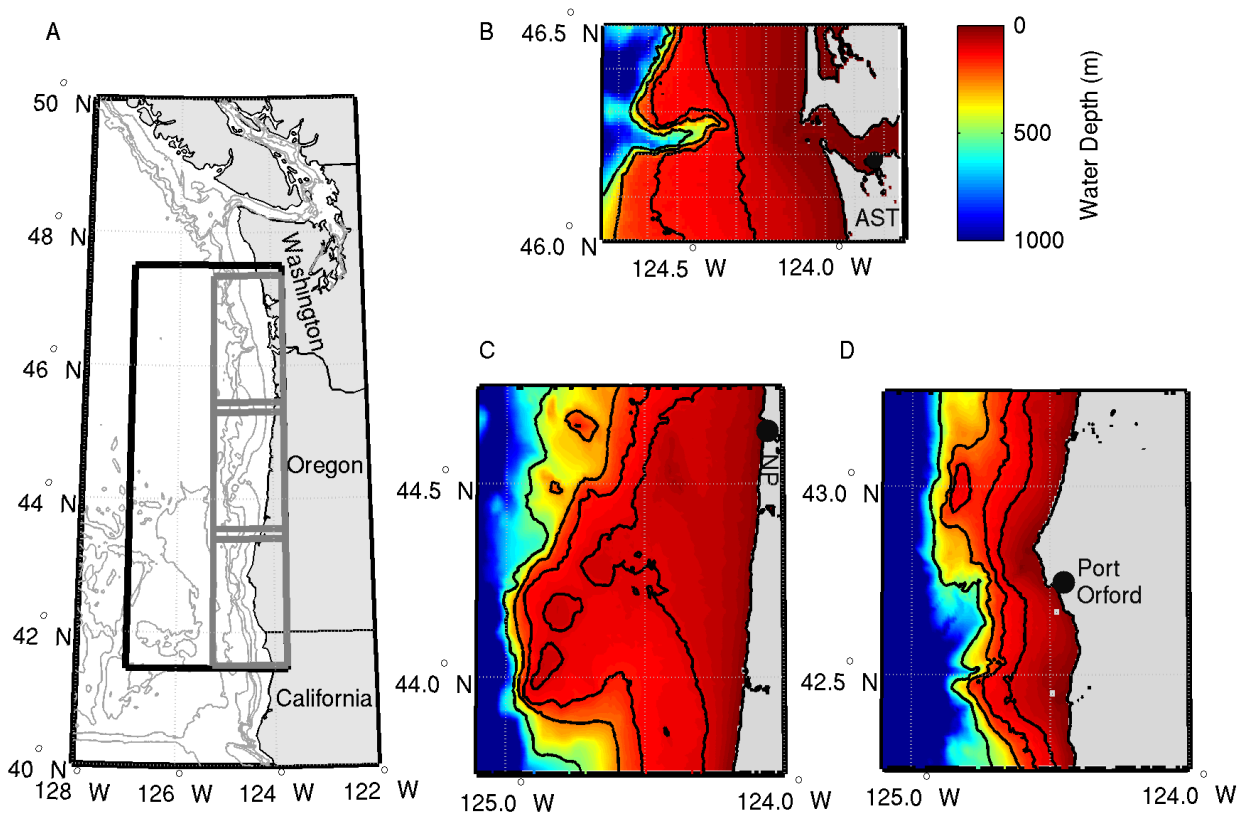

Figure 1. Study area and domain decomposition. A) The black box indicates the region covered by the third highest resolution grid while the gray boxes indicate the location of the higher resolution shelf scale grids. Contour lines at 100, 250, 500, 1000, and 3000 meters water depth. B) Astoria Canyon region, northern Oregon. AST stands for the city of Astoria. C) Offshore banks, near central Oregon. NP stands for the city of Newport. D) Southern Oregon region. B-D) Contour lines at 100, 150, 250 and 500 meters.
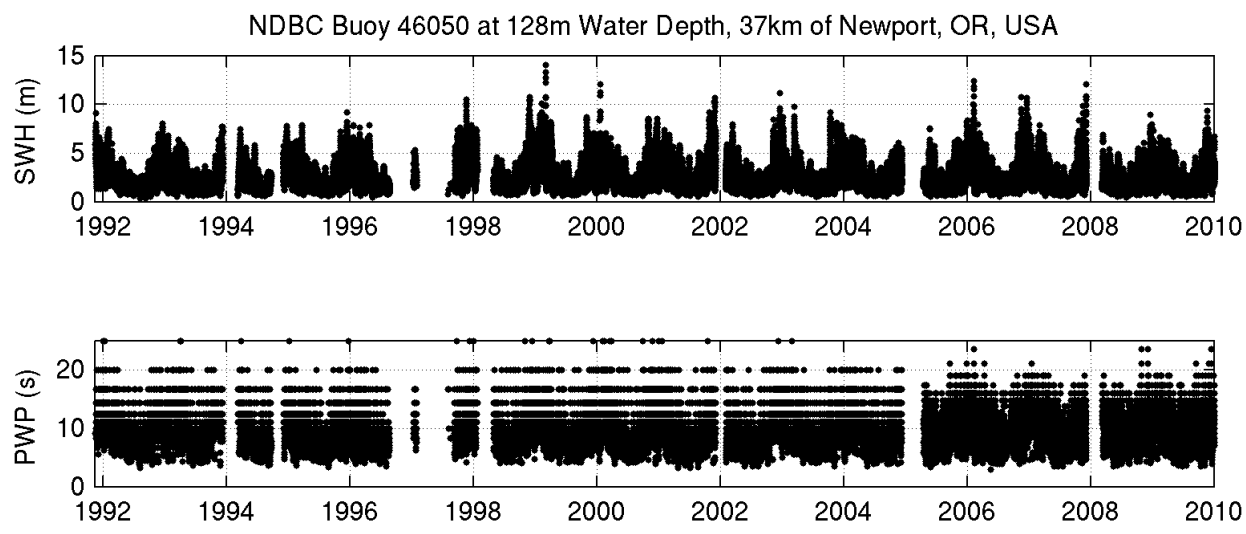

Figure 2. Wave climate at buoy 46050 near Newport, Oregon, USA. The top panel shows significant wave height (SWH) in meters and the bottom panel shows peak wave period (PWP) in seconds.

\section{Metrics}

To evaluate the model performance, a series of widely used statistical metrics were implemented. These metrics are the root-mean-squared error (RMSE)

$$
R M S E=\sqrt{\frac{\sum(M-E)^{2}}{N} ;}
$$

the normalized root-mean-squared-error (NRMSE)

$$
N R M S E=\sqrt{\frac{1}{N} \sum\left(\frac{M-E}{M}\right)^{2}} ;
$$




$$
\text { Bias }=\frac{1}{N} \sum E-M
$$

and linear correlation coefficient

$$
r^{2}=\left[\sum\left(M_{i}-\bar{M}\right)\left(E_{i}-\bar{E}\right)\right]^{2} / \sqrt{\sum\left(M_{i}-\bar{M}\right)^{2} \sum\left(E_{i}-\bar{E}\right)^{2}}
$$

where $M$ stands for measured data, $E$ for modeled data, $N$ for the number of observations, and the overline for averaged data. A perfect model run will report RMSE, NRMSE and Bias of 0 and linear correlation coefficient of 1 .

Throughout our discussion, we will compare SWH derived from wave spectra for both ground truth and modeled data. SWH is approximated from a wave spectrum $(S)$ as:

$$
S W H=4.004 \sqrt{m_{0}},
$$

where $m_{n}$ is the spectral moment defined as:

$$
m_{n}=\sum f_{i}^{n} S_{i} \Delta f_{i} \text {. }
$$

Spectral width as first proposed by Longuet-Higgins (1984) is also evaluated in this study, it is defined as:

$$
v^{2}=\frac{m_{0} m_{2}}{m_{1}^{2}}-1
$$

To evaluate the wind seas, the frequency spectrum was partitioned between high and low frequency parts. The cutoff frequency was selected according to:

$$
f_{\text {cut }}=\frac{g}{2 \pi} \frac{1}{1.5 U_{10}}
$$

as proposed by Hanson and Phillips (2001) where $g$ is the gravitational constant and $U_{l 0}$ is the wind speed at $10 \mathrm{~m}$ height.

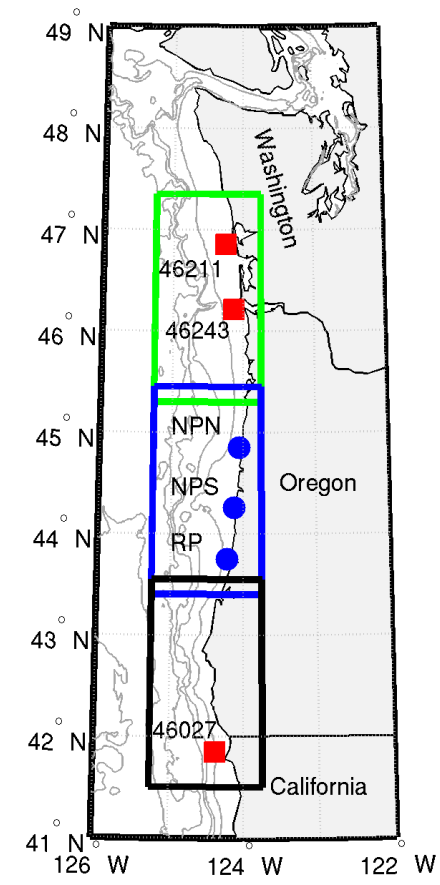

Figure 3 Ground truth data locations. The blue circles show the location of the short-term deployments while the red rectangles show the locations of the long term deployments. 


\section{Results}

Two hindcasts forced by analyzed GFS winds were performed to validate the model. These were performed for the autumn of 2009 and the summer of 2005 to match the AWAC deployments. NRMSE are low $(\mathrm{O}(0.20))$ and consistent among the hindcasted periods and water depths (see Table 1). High linear correlation coefficients, greater than 0.80 , provide confidence in the model implementation. These performance metrics are comparable with existing localized wave forecasting systems (AlvarezEllacuria et al. 2009; García et al. 2005; Salinas-Prieto et al. 2012; Sansana Silva et al. 2009).

\begin{tabular}{|c|cccccc|}
\hline \multicolumn{7}{|c|}{ Table 1. Significant wave height validation of the NearWW3 } \\
forecasting model. \\
\hline Time & ID & $N$ & $\begin{array}{c}\text { RMSE } \\
(\mathrm{m})\end{array}$ & NRMSE & $\begin{array}{c}\text { Bias } \\
(\mathrm{m})\end{array}$ & $\mathrm{r}^{2}$ \\
\hline & $\mathrm{RP}$ & 1729 & 0.55 & 0.20 & 0.12 & 0.91 \\
Autumn & 46211 & 2496 & 0.49 & 0.20 & 0.06 & 0.92 \\
2009 & 46243 & 661 & 0.57 & 0.17 & -0.01 & 0.91 \\
& 46027 & 2465 & 0.55 & 0.23 & 0.02 & 0.85 \\
\hline Summer & NPN & 1477 & 0.20 & 0.13 & -0.06 & 0.92 \\
2005 & NPS & 666 & 0.27 & 0.16 & -0.02 & 0.83 \\
\hline
\end{tabular}

To gain further insight on the nature of the strengths and weaknesses of the model, further analysis was performed with the AWAC data. The frequency spectrum was partitioned in a swell component and a wind sea component. The wind sea component was partitioned according to Equation 8 and the mature swell was taken as part of the spectrum with frequencies less than or equal to $0.1 \mathrm{~Hz}$. The intermediate part of the spectrum, often labeled as the young well, is not considered in this analysis. In general, it is expected that young swell error is a combination of wind sea and mature swell error (Hanson et al. 2009). The SWH was computed for the resulting frequency bands and the corresponding model performance was then evaluated. Table 2 shows the statistical results; overall the wind seas are under-predicted while the mature swells are over-predicted. Wind seas have higher correlation coefficients than the mature swell. In agreement with what Hanson et al. (2009) found in deep waters, the mature swell prediction carries most of the error. Figure 4A-B shows time series for modeled and measured wind seas and swell waves during the RP deployment. In general, locally generated waves in excess of $2.5 \mathrm{~m}$ are not captured in the model. Nevertheless, the shape of the time series is accurately captured and the small waves generated by these wind systems are also accurately represented. The swell wave height time series is matched by the model, but its over-prediction is evident.

\begin{tabular}{|c|c|c|c|c|c|c|c|c|c|}
\hline \multirow[b]{2}{*}{ ID } & \multicolumn{3}{|c|}{ Wind Seas } & \multicolumn{3}{|c|}{ Mature Swell } & \multicolumn{3}{|c|}{ Spectral Width } \\
\hline & $\begin{array}{c}\text { RMSE } \\
(\mathrm{m})\end{array}$ & $\begin{array}{c}\text { Bias } \\
(\mathrm{m})\end{array}$ & $r^{2}$ & $\begin{array}{c}\text { RMSE } \\
(\mathrm{m})\end{array}$ & $\begin{array}{c}\text { Bias } \\
(\mathrm{m})\end{array}$ & $r^{2}$ & RMSE & Bias & $r^{2}$ \\
\hline $\mathrm{RP}$ & 0.29 & -0.11 & 0.97 & 0.52 & 0.28 & 0.93 & 0.078 & -0.05 & 0.37 \\
\hline NPN & 0.19 & -0.14 & 0.97 & 0.19 & 0.10 & 0.90 & 0.117 & -0.06 & 0.45 \\
\hline NPS & 0.21 & -0.15 & 0.94 & 0.24 & 0.13 & 0.85 & 0.130 & -0.11 & 0.37 \\
\hline
\end{tabular}

Up to this point only temporal correlations have been used to evaluate the model performance. In the future, this model may be used as one of the tools to evaluate long term coastal behavior in the PNW. For these studies quantile-quantile (QQ) correlations are important. In order to evaluate this, the SWH was stored in $0.25 \mathrm{~m}$ bins for both the measured and modeled data. These were compared for the RP, NPN, and NPS stations providing correlation coefficients of 0.94, 0.95, and 0.98, respectively. Figure 4C shows the QQ performance at the RP station. Both the shape of the distribution and the magnitudes are accurately captured in this intermediate water station. Only in the high wave regions does the model appear to diverge significantly from the measured data.

\section{OPERATIONAL WAVE FORECASTS}

As previously mentioned NearWW3 is executed daily to produce 84 hour forecasts; however, by the time the computations are completed and the output processed, the forecast window is around 72 hours. Several products are made available via the NANOOS NVS interface (Risien et al. 2009) including color plots for each forecast hour; these provide large spatial coverage past the shelf break. Also, forecasts are provided at 25 meters water depth with a $2 \mathrm{~km}$ resolution along the region covered by the high-resolution grids. At these 233 locations, graphical representations of the frequency and 
direction spectra are given alongside SWH, wave period and wave direction forecasts. Finally, wave forecast information is stored at the location of several NDBC buoys to evaluate the model performance monthly and identify room for improvement. In addition, data is being provided for localized forecast applications that require wave forcing such as a wave-current interaction forecasting model at the mouth of the Columbia River in Oregon, USA by Kassem and Özkan-Haller (this issue).
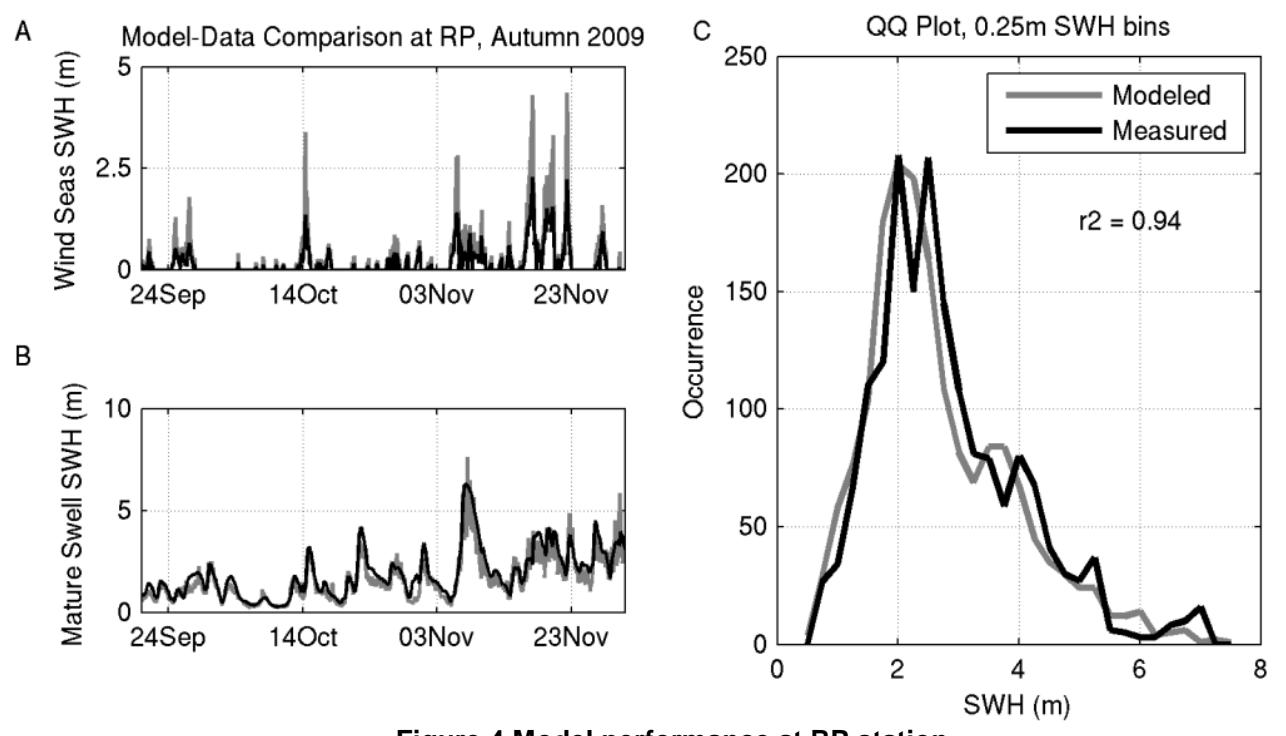

Figure 4 Model performance at RP station.

\section{SUMMARY}

In this article, we have presented a recent implementation of a high-resolution localized wave forecasting system for the Oregon and southwest Washington coast. This system provides scientists and decision makers in these coastal regions with an additional tool to improve their understanding of the regional wave climate. The recreational user community has access to high-quality localized wave forecasts via the user-friendly and free interface developed by NANOOS (at http://www.nanoos.org). Our implementation has been validated in intermediate water depths and a detailed description of the model's strengths and weaknesses is included. In general the model is skillful in predicting SWH and correctly matching the wave quantile distributions. However, the mature swell is over-predicted while the wind seas are under-predicted; suggesting further research is needed at the source term level. Future work will include expanding the operational products such as including coastal flooding forecasting and higher-resolution beach scale forecasts.

\section{ACKNOWLEDGMENTS}

The authors thank the Networked Association of Ocean Observing Systems (NANOOS) for their help with data visualization and outreach, in particular Craig Risien (Oregon State University), Troy Tanner (University of Washington), and Jonathan Allan (Oregon Department of Geology and Mineral Industries). We also want to acknowledge Jack Barth, Anthony Kirincich, Ata Suanda, and their team for providing the RP and NP datasets. Finally, we want to acknowledge the National Oceanic and Atmospheric Administration of the United States Department of Commerce for providing the Wavewatch III source code.

The work presented in this paper was funded by Oregon Sea Grant under Award Number NA10OAR4170059 and by the United States Department of Energy under Award Number DE-FG3608GO18179. Neither the United States Government nor any agency thereof, nor any of their employees, makes any warranty, expressed or implied, or assumes any legal liability or responsibility for the accuracy, completeness, or usefulness of any information, apparatus, produce, or process disclosed, or represents that its use would not infringe upon privately owned rights. Reference herein to any specific commercial product, process, or service by trade name, trademark, manufacturer, or otherwise does not necessarily constitute or imply its endorsement, recommendation, or favoring by the United States Government or any agency thereof. The views and opinions of the authors expressed herein do not necessarily state or reflect those of the United States Government or any agency thereof. 


\section{REFERENCES}

Alvarez-Ellacuria, A., A. Orfila, M. Olabarrieta, R. Medina, G. Vizoso, and J. Tintoré. 2010. A nearshore wave and current operational forecasting system, Journal of Coastal Research, 26 (3), 503-509.

Arinaga, R. A., and K. F. Cheung. 2012. Atlas of global wave energy from 10 years of reanalysis and hindcast data, Renewable Energy, 39 (1), 49-64.

García, P. C., C. F. Balseiro, E. Penabad, B. Gómez, and V. Pérez-Muñuzuri. 2005. One year validation of wave forecasting at Galician coast, Journal of Atmospheric and Ocean Science, 10 (4) 407-419.

Hanson, J.L., and O. M. Phillips. 2001. Automated analysis of ocean surface directional wave spectra, Journal of Atmospheric and Oceanic Technology, 18, 277-293.

Kassem S., and H. T. Özkan-Haller. 2012. Forecasting the wave-current interactions at the mouth of the Columbia River, OR, USA, Proceedings of the $33^{\text {rd }}$ International Conference on Coastal Engineering, this issue.

Kirincich, A. R., S. J. Lentz, J. A. Barth. 2009. Wave-driven inner-shelf motions in the Oregon coast, Journal of Physical Oceanography, 39 (11), 2942-2956.

Longuet-Higgins, M. S. 1984. Statistical properties of wave groups in a random sea state, Philosophical Transactions of the Royal Society of London. Series A, Mathematical and Physical Sciences, 312 (1521), 219-250.

Menéndez, M., F. J. Méndez, I. J. Losada, and N. E. Graham. 2008. Variability of extreme wave heights in the northeast Pacific Ocean based on buoy measurement, Geophysical Research Letters, 35,6 pp.

Risien, C. M., J. C. Allan, R. Blair, A. V. Jaramillo, D. Jones, P. M. Kosro, D. Martin, E. Mayorga, J. A. Newton, T. Tanner, and S. A. Uczekaj. The NANOOS visualization system: aggregating, displaying and serving data, Proceedings of the MTS/IEEE Oceans 2009, 1-9.

Ruggiero, P., P. D. Komar, and J. C. Allan. 2010. Increasing wave heights and extreme value projections: The wave climate of the U.S. Pacific Northwest, Coastal Engineering, 57, 539-552.

Salinas-Prieto, J. A., R. Padilla-Hernández, F. Oropeza-Rosales, and R. Lobato-Sánchez. 2012. Sistema de pronóstico automatizado de oleaje, Tecnología y Ciencias del Agua, 3 (1), 45-67.

Sansana Silva, F., J. P. Pinto, and S. Almeida. 2009. Operational wave forecasting system for the Portuguese coast, Journal of Coastal Research, SI 56, 1055-1059.

Sela, J. G. 1980. Spectral modeling at the national meteorological center. Monthly Weather Review, 108 (9), 1279-1292.

Tolman, H. L. 2002. Validation of WAVEWATCH III version 1.15 for a global domain, NOAA/NWS/NCEP/OMB (Nr. 213), 33 pp.

Tolman, H. L. 2008. A mosaic approach to wind wave modeling, Ocean Modelling, 25 (1-2), 35-47.

Young, I. R., S. Zieger, and A. V. Babanin. 2011. Global trends in wind speed and wave height, Science, 332 (6028), 451-455. 